I Universidade Federal de São Paulo (Unifesp), Departamento de Medicina

Preventiva, São Paulo, SP, Brasil

richard.miskolci@unifesp.br

https://orcid.org/000o-0002-6405-559I

Richard Miskolci'

\title{
O MEDO DA PANDEMIA COMO QUESTÃO SOCIOLÓGICA
}

As ruas vazias de São Paulo no outono de 2020 apresentam ao nosso olhar um cenário incomum. Um ou outro carro passa, em velocidade desnecessariamente acelerada e, vez ou outra, alguém atravessa a rua, apressado, usando máscara e com o corpo encolhido, como a se proteger não do vento frio do entardecer, mas de um inimigo invisível. Imagem que a pandemia da covid-ı e a medida sanitária do isolamento social não decifram completamente. O transeunte de máscara, em passo apressado e corpo encolhido, evoca a experiência comum do medo que nos tomou desde março, quando uma espécie de noite imaginária escureceu nossos dias. Medo individualmente vivido, mas que nesta curta reflexão buscarei abordar em suas raízes coletivas e históricas.

Há muito que o Ocidente reage com medo ou pânico a situações inesperadas ou com consequências preocupantes. O falecido Jean Delumeau reconstituiu parte do fenômeno em seu clássico História do medo no Ocidente (publicado originalmente em I978), obra que aborda algumas das principais reações coletivas a perigos, reais ou imaginários, entre i 300 e I800. Delumeau (2009) afirma que o medo é fundamentalmente medo da morte, aqui compreendida como algo cultural que demanda associar os temores da peste aos das consequências da Reforma Protestante. A despeito de tudo o que os singulariza, esses dois temores implantaram coletivamente uma dúvida individualmente vivida sobre a salvação da alma mais do que a do corpo.

A peste negra exterminou de um a dois terços da população europeia em meados do século XIV, espalhando, junto com as mortes, o temor de uma 
ameaça (sobre)natural. Hoje vemos a peste bubônica como uma ameaça biológica, mas naqueles tempos a natureza se mesclava a outras forças, o que é atestado pelo nome dado à doença, derivado de um poema belga que atribuía a origem da enfermidade a uma conjunção de Júpiter e Saturno. A peste legou ao Ocidente o medo esporadicamente avivado de ameaças mortais à vida dos povos. A Reforma Protestante, por sua vez, instaurou mais uma divisão no cristianismo em que a escolha entre seguir Lutero ou o papa colocava o fiel diante de um dilema que definiria se salvava sua alma ou abraçava a danação. Uma mudança cultural instaurou um novo tipo de medo coletivo, de ordem cultural, que demanda uma resposta individualizada. Cada pessoa é colocada à frente de um dilema e confrontada com as consequências de sua decisão.

O Ocidente, moldado culturalmente por essa história, parece responder com medo a ameaças que, no Oriente, despertam outra resposta. Quiçá o individualismo entre nós o explique, assim como a valorização do coletivo ajude a entender a forma como nações do leste têm enfrentado desafios similares com mais calma e resiliência. Estudos podem avaliar se tal distinção condiz com a realidade ou é mais uma das criações de nosso orientalismo. No entanto, análises que nos confrontam com algo admirável e superior na alteridade nascem do espírito crítico capaz de nos colocar em questão e merecem ser trazidas ao discurso.

Historicamente, os medos coletivos do Ocidente se sucederam e se transformaram de modo que hoje predominam formas mistas de temor, já que até as catástrofes naturais resultam de consequências da ação humana, como o uso predatório do meio ambiente. O medo também se integrou/domesticou no cotidiano das sociedades contemporâneas, na forma calculada do risco. De qualquer modo, o temor coletivo não se extinguiu - tampouco nada aponta para sua superação. Cabe-nos reconhecer seu papel na vida social, uma presença jamais desejada que impacta nossas projeções do futuro moldando a forma como agimos individual e coletivamente.

$\mathrm{Na}$ sociologia, Adorno e Horkheimer (I997) refletiram sobre o medo em sua nota-posfácio a Dialética do esclarecimento intitulada "Sobre a teoria dos fantasmas". Na junção da teoria psicanalítica freudiana a uma abordagem da sociologia histórica, os pensadores alemães propõem compreender a sociedade presente levando em consideração a relação que cria com seu passado, seus mortos e esquecidos. De forma sintética, os autores afirmam que a repressão da memória em relação aos que padeceram, especialmente de forma injusta e violenta, não elimina seu peso sobre os viventes. A culpa permanece a rondar a coletividade em temores de que o passado retorne como ameaça.

Talvez o que os medos coletivos tenham em comum seja o poder de questionar concepções idealizadas sobre o que cremos ser hoje, e a ameaça a que reagem envolve nossa relação com o passado e a alteridade. A partir da década de I960, a teoria dos pânicos morais auxiliou a sociologia a compreender as reações desproporcionais que a coletividade dispara diante de alguma mudança 
social que grupos de interesse apresentam como um perigo ou ameaça. Na década de I980, a crescente visibilidade homossexual levou empreendedores morais a disparar pânicos sexuais, dos quais o em torno da epidemia de HIV-aids foi o mais disseminado globalmente. Os medos coletivos, portanto, tornaram-se ferramentas de grupos de interesse para moldar a opinião pública a favor de suas causas morais e políticas.

Historicamente, as sociedades ocidentais passaram do medo de agentes (sobre)naturais aos culturais, como a Reforma Protestante, até os políticos, como o grande medo que tomou a França rural, em finais do século XVIII, e os temores sobre Canudos, no Brasil recém-republicano e pós-escravista do final do XIX. Assim, cabe o cuidado para não reificar o fenômeno do medo coletivo como se fosse sempre o mesmo a se repetir ou reatualizar. O que pode se manter nas singularidades de cada momento histórico e enquadramento cultural são os já mencionados medo do passado e da alteridade. Ambos são forças a contestar o que imaginávamos ser antes de sermos assombrados por algo.

A socióloga norte-americana Avery F. Gordon (2008) considera que ser assombrado é uma forma de mediação, um processo que liga um indivíduo a uma instituição, a história à biografia, a estrutura social ao sujeito. Nesse sentido, o que tratei até aqui como medo envolve a incorporação analítica de relações entre os sujeitos e a coletividade que vão além das puramente racionais e visíveis. Trata-se de tomar a sério a crítica foucaultiana às ciências humanas em As palauras e as coisas (2016), reconhecendo que não podemos dar as costas ao inconsciente na análise social. Uma leitura histórica e sociológica dele é possível assim como uma sociologia afeita aos elementos emocionais da vida coletiva pode colaborar para compreender melhor fenômenos como o da pandemia.

Quando o que era risco se materializou em perigo epidemiológico, a incerteza gerou cálculos, projeções e probabilidades sobre a curva da epidemia, mas também instaurou um estado de crise que vincula a coletividade es sujeitos. Atualmente, o vocabulário médico-sanitário busca domesticar a crise instaurada pela covid-I 9 na familiaridade reconfortante do slogan Fique em Casa e nos conselhos de especialistas para manter a rotina e cuidar da saúde mental. A quarentena, tecnologia sanitária que Michel Foucault (2006) data da eclosão da peste em território francês, voltou a ser acionada com fins de saúde pública que evocam paralelos sombrios entre o presente e o passado.

Ainda que o paralelo mais comum do coronavírus seja com a influenza mortal de I9I8, as incertezas econômicas também evocam um cenário futuro similar ao de um pós-guerra. Emergem ansiedades que abalam as tentativas de manter um cotidiano ordeiro, em meio à emergência, enquanto o fenômeno antigo das teorias da conspiração alimenta o negacionismo científico que se manifesta mesclado à xenofobia em teses que atribuem nacionalidade ao vírus, na recusa em reconhecer a necessidade do isolamento social e, sobretudo, na resposta simples e mágica de que a cura estaria em um remédio milagroso. 
Toda pandemia se expressa de forma singular em cada nação, em termos epidemiológicos e culturais, obrigando-nos a reconhecer qual a relação que a do coronavírus instaura no Brasil, entre nós e com nosso passado. Se na Europa, menos desigual socioeconomicamente, a infecção atingiu fortemente os idosos, aqui ela pode ceifar mais vidas entre os pobres e desnutridos. Uma emergência epidemiológica poderia nos fazer reconhecer fragilidades como coletividade e nossa incontornável interdependência, mas nosso passado mostra que a sociedade brasileira sempre optou por tratar desigualmente os concidadãos relegando a maioria à miséria e à vulnerabilidade. Passado inconveniente a assombrar nossas elites, privilegiadas econômica e sanitariamente, durante um isolamento que radicaliza sua condição social de distanciamento das classes menos favorecidas, seus dramas e suas mortes.

Recebido em 25/I0/2020 | Aprovado em 06/05/202I

Richard Miskolci é professor titular de sociologia da Unifesp, pesquisador do CNPq e coordenador do Quereres - Núcleo de Pesquisa em Diferenças, Direitos Humanos e Saúde. Doutor em sociologia pela USP, foi pesquisador visitante na Universidade da Califórnia e na Universidade de Michigan. É coordenador da área de Ciências Sociais e Humanas em Saúde do Departamento de Medicina Preventiva da Escola Paulista de Medicina e pesquisa desinformação e saúde a partir da pandemia de covid-ı 9 no Brasil. Seu livro mais recente é Batalhas morais: política identitária na esfera pública técnico-midiatizada. 


\section{REFERÊNCIAS}

Adorno, Theodor W. \& Horkheimer, Max. (I997). Dialects of enlightenment. New York: Continuum.

Delumeau, Jean. (2009). História do medo no Ocidente (1300I800). São Paulo: Cia. das Letras.

Foucault, Michel. (20I6). As palauras e as coisas: uma arqueologia das ciências humanas. São Paulo: Martins Fontes. Foucault, Michel. (2006). O nascimento da medicina social. In: Microfísica do poder. São Paulo: Graal.

Gordon, Avery F. (2008). Ghostly matters: haunting and the sociological imagination. Minneapolis: University of Minnesota Press. 


\section{O MEDO DA PANDEMIA COMO QUESTÃO \\ SOCIOLÓGICA}

\begin{abstract}
Resumo
A partir da pandemia da covid-I9 de 2020, o artigo explora o papel cultural do medo em termos históricos e sociológicos. Baseado em fontes da teoria crítica, discute como o medo coletivo incita respostas que associam projeções de futuro com temores sobre a alteridade e o passado. A análise do medo da pandemia busca a incorporação analítica de aspectos que vão além dos puramente racionais e visíveis de maneira a desenvolver uma sociologia afeita aos elementos emocionais e fantasmáticos da vida coletiva.
\end{abstract}

\section{THE FEAR OF THE PANDEMIC AS A SOCIOLOGICAL MATTER}

Abstract

Based on the pandemic of covid-I9 in 2020, this paper analyzes the cultural role of fear in historical and sociological terms. Through critical theory's sources, it analyzes how collective fear incites answers that associate projections of the future with fears about alterity and the past. The analysis of the fear of the pandemic tries to incorporate theoretically aspects that go beyond the purely rational and visible ones to develop a sociology nearer the emotional and fantasmatic elements of collective life.
Palavras-chave

Medo;

passado;

alteridade;

pandemia;

covid-I9.

Keywords

Fear;

past;

alterity;

pandemic;

covid-I9. 